\title{
A GESTÃO ESCOLAR DEMOCRÁtICA NA PERSPECTIVA FREIREANA
}

\author{
Antonio Amorim ${ }^{1}$ \\ Eliane Silva Souza ${ }^{2}$ \\ Rose Santos de Jesus Pereira ${ }^{3}$
}

\section{RESUMO}

O artigo discute a gestão escolar na perspectiva freireana a partir do estudo de casos múltiplos envolvendo escolas públicas de Salvador, Bahia, utilizando abordagem qualitativa e baseado na questão de como a gestão escolar municipal tem efetivado a gestão democrática considerando a perspectiva freireana de participação popular. O estudo visou refletir acerca da concretização da gestão escolar democrática envolvendo a participação dos sujeitos da Educação de Jovens e Adultos (EJA). A pesquisa demonstrou que para alcançar uma perspectiva freireana na gestão escolar é necessário que o diálogo e a participação estejam presentes, condições essenciais para que a democracia seja vivida e experienciada com a participação efetiva dos sujeitos da EJA na condução dos processos de gestão da escola, com vistas a auferir uma educação mais humanizadora,

1 Doutor em Psicologia pela Universidade de Barcelona. Professor Titular Pleno da Universidade do Estado da Bahia. Pós-Doutorado em Difusão do Conhecimento pela UFBA. Líder do Grupo de Pesquisa Gestão, Organização, Tecnologia e Políticas Públicas em Educação - GP-GEPE. ORCID: http://orcid.org/0000-0003-3236-9139. Email: antonioamorim52@gmail.com

2 Mestra pelo Programa de Educação de Jovens e Adultos da Universidade do Estado da Bahia (UNEB). Professora na Rede Municipal de Ensino de Salvador/BA. Membro do Grupo de Pesquisa Interface: Investigação Interdisciplinar sobre a Formação do Educador. ORCID: http://orcid.org/0000-0002-8203-6255. Email: elianesouza@outlook.com

3 Mestranda do Programa de Educação de Jovens e Adultos da Universidade do Estado da Bahia (UNEB) Coordenadora na Rede Municipal de Ensino de Salvador/BA. ORCID: http://orcid.org/0000-0003-0249-0616. E-mail: rosebecasami@hotmail.com 
includente e que tencione atender aos reais anseios dos estudantes.

Palavras-chave: Gestão escolar democrática. Diálogo. Educação de Jovens e Adultos.

\section{DEMOCRATIC SCHOOL MANAGEMENT FROM THE FREIREAN PERSPECTIVE}

\section{ABSTRACT}

The article discusses the school management from Freire's perspective through the study of multiple cases involving public schools in Salvador, Bahia, using a qualitative approach and based on the question of how municipal school management has implemented democratic management considering the Freirean perspective of popular participation. The study aimed to reflect on the implementation of democratic school management involving the participation of the subjects of the Youth and Adult Education (YAE). Research has shown that in order to achieve a Freirean perspective in school management, dialogue and participation must be present, essential conditions for democracy to be lived and experienced with the effective participation of the subjects of YAE in the conduction of school management processes, with the purpose of obtaining a more humanizing and inclusive education, that intends to meet the real concerns of the students

Keywords: Democratic school management. Dialogue. Youth and Adult Education. 


\section{LA GESTIÓN ESCOLAR DEMOCRÁTICA EN LA PERSPECTIVA DE FREIRE}

\section{RESUMEN}

El artículo analiza la gestión escolar en la perspectiva de Freire basada en estudio de casos múltiples que involucran escuelas públicas en Salvador, Bahía, utilizando un enfoque cualitativo basado en la cuestión de cómo la gestión escolar municipal ha implementado la gestión democrática considerando la perspectiva de Freire de participación popular. El estudio tuvo como objetivo reflexionar sobre la implementación de la gestión escolar democrática que involucra la participación de sujetos de la Educación de Jóvenes y Adultos (EJA). La investigación ha demostrado que, para lograr una perspectiva de Freire sobre la gestión escolar, debe haber el diálogo y la participación, condiciones esenciales para que la democracia sea experimentada con la participación efectiva de los sujetos de EJA en la conducción de los procesos de gestión escolar, con el fin de obtener una educación más humanizada e inclusiva que tenga la intención de satisfacer los verdaderos deseos de los estudiantes.

Palabras clave: Gestión Escolar Democrática. Diálogo. Educación de Jóvenes y Adultos.

\section{INTRODUÇÃO}

O presente estudo emerge das leituras e das discussões envolvendo a gestão da escola de Educação de Jovens e Adultos (EJA), que são propiciadas pelo itinerário formativo e investigativo desenvolvido no Mestrado Profissional em Educação de Jovens e Adultos (MPEJA), através da linha de pesquisa Gestão Educacional e Tecnologias da Comunicação. No processo reflexivo vivenciado surge a problemática da participação dos sujeitos da EJA nos processos de 
gestão escolar, por isso promovemos a seguinte questão: como a gestão escolar municipal em Salvador/BA tem efetivado a gestão democrática considerando a perspectiva freireana de participação popular?

A partir deste questionamento, o estudo buscou, enquanto objetivo principal, refletir acerca da efetivação da gestão escolar democrática na perspectiva freireana envolvendo a participação dos sujeitos da EJA. Desta forma, a efetivação da investigação visou identificar os mecanismos de participação que têm sido instituídos na gestão escolar municipal, para empreender a gestão democrática numa perspectiva freireana e analisar a concretização da participação dos sujeitos da EJA, no desenvolvimento de processos de gestão democrática, na Rede Municipal de Ensino de Salvador/Ba.

Este estudo apresenta uma discussão necessária à medida que a escola de EJA precisa estruturar e efetivar a gestão escolar envolvendo os sujeitos, especialmente os estudantes, para promover mecanismos de participação popular, em todos os processos da gestão. Operando os processos da gestão com os sujeitos, a escola concretiza a experiência democrática, que deve ser pautada no diálogo e na participação horizontalizada, potencializando a efetivação de uma educação humanizadora, que seja baseada no desenvolvimento do pensamento crítico e na atuação efetiva dos sujeitos. Tudo isso, com vistas a operar as mudanças em sua realidade objetiva e na sociedade, contribuindo, desta forma, para uma melhor qualidade educacional e de participação social.

Assim, o estudo está organizado por esta introdução, onde destacamos a temática estudada, a questão e os objetivos da investigação. Na sequência apresentamos o percurso metodológico que foi desenvolvido a partir da abordagem da pesquisa qualitativa, bem como o contexto e os sujeitos investigados. Na seção seguinte apresentamos uma revisão conceitual, que se constitui como base para a discussão acerca da gestão escolar numa perspectiva freireana. A discussão dos resultados e a análise das três experiências de gestão investigadas são apresentadas na sequência. O estudo é finalizado com as considerações tecidas a partir da investigação e análise dos resultados, finalizando com a apresentação das referências utilizadas. 


\section{PERCURSO METODOLÓGICO E CONTEXTO DA PESQUISA}

O estudo foi desenvolvido a partir da abordagem qualitativa a qual, de acordo com Chizzotti (2018), envolve a interrelação orgânica entre o mundo real e os sujeitos, onde estes interpretam os fenômenos Ihes atribuindo significados. Assim, o objeto da investigação é marcado pela dinâmica relacional que mantém com a ação criadora e interventiva dos sujeitos.

Para Minayo (2016), o conhecimento é uma produção social e histórica dos sujeitos e dos diferentes grupos que constroem a sua existência de maneiras diversas, mas que mantém pontos de convergência em virtude de estarem vivendo num mundo que é influenciado uns aos outros através da comunicação humanizadora. Desta forma, a abordagem qualitativa se apresenta como sendo a mais adequada à investigação, pois propicia a compreensão de processos dinâmicos, que são vividos pelos grupos sociais e, segundo Richardson (2015), trata-se de uma abordagem investigativa que pode contribuir com a construção de processos de mudanças de determinados grupos sociais.

O procedimento estratégico adotado foi o estudo de caso múltiplo. De acordo com André (2013), o estudo de caso focaliza o aspecto unitário, valoriza a análise em profundidade, propiciando, neste sentido, a descrição de ações e de comportamentos com base na imersão em profundidade. Para Yin (2014), a partir do estudo de caso as questões que envolvem o como e por que podem focalizar os acontecimentos e os fenômenos contemporâneos e, a partir do estudo de caso múltiplo, é possível fortalecer a investigação e a análise contrastiva dos casos estudados.

Enquanto dispositivos utilizados na produção de informações envolvemos o questionário, que possibilita 0 acesso aos conhecimentos, às crenças e aos sentimentos dos sujeitos, bem como, aos seus valores, desejos e experiências do passado, tendo como vantagem o acesso a um grande número de sujeitos presente (GIL, 2019). Destacamos ainda o uso da observação participante, que, de acordo com Haguette (2013), se constitui como a melhor forma de captar os sentidos encobertos da ação dos sujeitos. 
As etapas desenvolvidas ao longo do itinerário investigativo foram as seguintes: a exploratória, onde estabelecemos os contatos iniciais com as escolas estudadas, o diálogo e a localização dos participantes da pesquisa e a definição dos dispositivos para a produção das informações. Na segunda etapa realizamos a delimitação do foco do estudo, a seleção de aspectos a investigar e efetivamos a produção de informações. Por fim, realizamos a análise sistemática das informações, envolvendo a elaboração de relatórios iniciais de pesquisa e análise dos resultados.

O estudo envolveu três escolas da Rede Municipal de Ensino de Salvador, Bahia. A primeira localizada no bairro do Doron, a segunda localizada no bairro do Rio Vermelho e a terceira em Tancredo Neves. A primeira, trata-se de uma escola de porte grande e especial, pois tem 947 estudantes matriculados em três turnos. Oferece Educação Infantil, Ensino Fundamental Anos Iniciais, EJA I e II e conta com oferta de Atendimento Educacional Especializado (AEE). Além do ensino regular tem, nos turnos da manhã e da tarde, turmas que são atendidas com programas de regularização de fluxo escolar, totalizando nos três turnos trinta e seis turmas.

A escola funciona em prédio próprio e sua estrutura física envolve dezoito salas de aula, pátio coberto, pátio descoberto, quadra de esporte coberta, quadra de esporte descoberta, refeitório, sala da diretoria, sala de leitura, sala de professor, sala de recursos multifuncionais, sala de secretaria, banheiros para estudantes e servidores e almoxarifado. Os estudantes contam com alimentação produzida na escola sob supervisão da gestão escolar. $O$ índice de aprovação da escola é de $79 \%$, abandono 3,6\% e reprovação $17,4 \%$. Em 2017, a escola alcançou 4,7 no IDEB, superando 0,1 ponto da meta projetada.

O grupo de professores totaliza quarenta e oito sujeitos envolvendo pedagogos e professores das diversas licenciaturas. Há coordenador pedagógico nos três turnos, secretária escolar, três vicediretoras e diretora. Observamos que há a presença efetiva de equipe gestora nos três turnos da escola e a escolha desta equipe ocorreu por meio de eleição. Além disso, como a gestora também é coordenadora na escola, atuando com uma carga horária total de $60 \mathrm{~h}$, a sua participação se efetiva em todos os turnos. 
A segunda escola tem porte médio, funciona nos três turnos com 346 estudantes matriculados. Oferece Educação Infantil, Ensino Fundamental Anos Iniciais, EJA I e também conta com oferta de programa de regularização de fluxo no turno da tarde. Na oferta nos três turnos totalizam dezenove turmas. Há, também, a oferta de Atendimento Educacional Especializado (AEE) na escola. A escola conta com trinta professores. Há coordenador pedagógico nos três turnos, sendo que um atua no diurno e o outro no noturno, secretária escolar, três vice-diretoras e diretora, contando com equipe gestora nos três turnos de funcionamento. A escolha da equipe gestora ocorreu por meio de eleição.

No período em que o estudo foi desenvolvido a escola estava passando por reforma e o seu funcionamento ocorria em um espaço provisório, situado no mesmo bairro, Rio Vermelho, cuja estrutura física envolvia nove salas de aula, pátio coberto, sala de professor, sala de recursos multifuncionais, biblioteca, cantina e secretaria. A estrutura física do prédio próprio da escola envolve nove salas de aula, parque infantil, pátio coberto, quadra de esporte coberta, sala de dança, biblioteca, cantina, refeitório, laboratório de informática, sala da diretoria, um elevador para cadeirantes, banheiros adaptados, sala de professor, sala de recursos multifuncionais e sala da secretaria.

Os estudantes contam com alimentação produzida na escola sob supervisão da gestão escolar, bem como de uma empresa terceirizada que oferece assessoramento por meio de um profissional da área de nutrição. O índice de aprovação da escola é de 94\%, reprovação 6\% e não há registro de abandono. Em 2017 a escola alcançou 6,3 no IDEB, superando 1,6 pontos da meta projetada de 4,7 .

A terceira escola tem porte médio, funciona apenas durante o dia e envolve um quantitativo de 44 estudantes matriculados em turmas de EJA I. São nove turmas, das quais oito atendem exclusivamente a estudantes do sexo masculino e ficam situadas na sede da escola e uma atende exclusivamente a estudantes do sexo feminino e funciona em uma sala anexa, fora da estrutura da escola. A escola funciona em um prédio cedido e sua estrutura física envolve seis salas de aula, diretoria, sala de leitura e almoxarifado. Tem o 
banheiro de estudantes e servidores, uma sala de aula e a cozinha ficam fora da estrutura da escola.

Essa terceira escola atua exclusivamente com estudantes privados de liberdade oriundos de todo o estado da Bahia, em virtude de estarem cumprindo medida socioeducativa em Comunidades de Atendimento Socioeducativo na capital do estado. O funcionamento da escola envolve dezesseis professores, coordenador pedagógico, secretária escolar, duas vice-diretoras e diretor. Há a oferta de alimentação escolar aos estudantes, que é fornecida por uma empresa terceirizada. Observamos que a escola conta com equipe gestora nos dois turnos de funcionamento e a mesma foi indicada pela secretaria municipal da educação. Como a escola funciona exclusivamente com EJA não tem avaliação do IDEB, já que esta modalidade não participa da Prova Brasil.

A pesquisa foi desenvolvida entre os meses de junho e agosto de 2019 e envolveu vinte e um sujeitos, sendo sete estudantes, seis professores, dois coordenadores, três vice-diretores e três diretores. No grupo de trabalhadores da EJA, 93\% são mulheres e $7 \%$ homens. O grupo tem idade entre 39 a 56 anos, sendo que $57 \%$ atuam com classes de EJA no noturno, enquanto $43 \%$ atuam com classes de EJA no contexto da socioeducação com privação de liberdade no diurno.

Todos os trabalhadores da EJA participantes da pesquisa têm formação inicial em pedagogia, são servidores públicos e $93 \%$ atuam em educação nos últimos dez anos, enquanto $7 \%$ atuam entre sete anos e meio a dez anos. O tempo de atuação na EJA de $50 \%$ desses sujeitos é de cinco a dez anos, $43 \%$ atuam com mais de dez anos e $7 \%$ atuam na EJA de dois e meio a cinco anos.

No grupo de estudantes da EJA, 57\% são mulheres e $43 \%$ homens. O grupo tem idade entre 15 a 66 anos e são todos da primeira e da segunda escolas estudadas, uma vez que na terceira escola não foi possível envolver a participação dos estudantes em virtude do tempo necessário para cumprir todo o protocolo de autorização da participação dos mesmos na pesquisa. Todos são estudantes da EJA I no noturno e durante o dia atuam como empregada doméstica, auxiliar de produção, mestre de obras, dona de casa e um apenas estuda. 
DIÁLOGO, PARTICIPAÇÃO E DEMOCRACIA: base para a gestão na perspectiva freireana

A discussão acerca da gestão escolar democrática na perspectiva freireana implica na revisão das concepções de diálogo, de participação e de democracia. Neste sentido, sedimentamos o estudo em Freire (2019), autor que compreende as mulheres e os homens enquanto seres histórico-sociais, sujeitos capazes de atuar no mundo comparando, valorando, realizando intervenções, fazendo escolhas, tomando decisões e instituindo rupturas.

Para Freire (2019), o mundo é construído pela existência curiosa e inteligente de sujeitos históricos que interferem na realidade objetiva. Desta forma, somos "[...] capazes de intervir na realidade, tarefa incomparavelmente mais complexa e geradora de novos saberes do que simplesmente a de nos adaptar a ela" (FREIRE, 2019, p.77). Assim, a ação dos sujeitos é essencialmente transformadora do mundo e da sua realidade objetiva, haja vista que assume a posição de ruptura da realidade posta, desalienando-se, ao mesmo tempo em que contribui para a desalienação de seus pares. Essa tomada de consciência, que é mediada pelo diálogo, favorecerá à organização crítica do pensamento desses sujeitos, levando-os a se tornarem agentes transformadores dentro de uma sociedade desigual.

Torna-se claro, na análise histórica que se faz da sociedade, o esforço orquestrado pelos opressores, a fim de que se mantenha a hegemonia de classes, que os oprimidos permaneçam na condição de alheação, que continuem na obscuridade de seus pensamentos e possam ser facilmente manipulados. Assim, uma pequena parcela da esfera social continuará com muito, detendo o capital financeiro e intelectual, enquanto que a grande massa segue com pouco ou quase nada, alheada dos direitos mais básicos de cidadania.

Daí, na concepção de Freire (2019), a importância da emancipação dos sujeitos para a participação ativa, política e pedagogicamente falando, a fim de que sejam preparados para, de forma democrática, tecerem suas escolhas conscientes e críticas, tanto no âmbito da escola quanto nas questões da organização 
social, e desenvolverem a capacidade de examinar, acompanhar e inferir nas atitudes e na tomada de decisões de seus eleitos.

Nesse sentido, Torres (2013), à luz do pensamento freireano, afirma que a concepção de democracia está intrinsecamente ligada à de ideia de cidadania democrática e que esta precisa ser desenvolvida por muitos, a fim de que estejam preparados para exercê-la, efetivamente. Urge a necessidade de que a educação seja protagonista do que ora expomos, para que haja a participação, de forma igualitária, de todos os indivíduos que compõem a sociedade, a fim de que prepondere a isonomia nesse processo.

Freire (2018) afirma que o diálogo é um fenômeno humano e a ele é inerente a palavra constituída por duas dimensões: ação e reflexão. De acordo com o autor estas dimensões apresentam "[...] uma interação tão radical que, sacrificada, ainda que em parte, uma delas, se ressente, imediatamente, a outra. Não há palavra verdadeira que não seja práxis. Daí, que dizer a palavra verdadeira seja transformar o mundo" (FREIRE, 2018, p. 107). Nesta perspectiva, o diálogo e a condição dos sujeitos dizerem sua palavra são princípios essenciais à ação interventiva e transformadora.

Mas, à condição de os sujeitos dizerem a sua palavra é essencial que se estenda a todos os sujeitos, que isto não se resuma a privilégio de alguns. É fundamental que todos os sujeitos possam dizer a palavra verdadeira, que é a práxis, conjuntamente (FREIRE, 2018). Assim, temos o diálogo a partir do encontro de sujeitos em uma relação horizontalizada. Freire (2018) define o diálogo enquanto exigência existencial e por meio do seu exercício criamos a condição da socialização da diversidade dos conhecimentos e dos saberes.

É por meio do diálogo e da condição de os sujeitos dizerem a palavra verdadeira que se legitima a sua participação nos diversos espaços produtivos, bem como, na sociedade de um modo geral. $\mathrm{Na}$ escola da EJA onde se acredita dominar os conhecimentos e os saberes essenciais aos grupos populares, não será possível compreender o mundo dos sujeitos e da escola adotando-se uma postura autoritária, que nega a efetiva participação dos seus estudantes. De acordo com Freire (2019, p.124), a "[...] afirmação do educando como sujeito de conhecimento", somente será possível 
quando a escola estiver aberta à escuta desses sujeitos, com a criação de espaços para o diálogo entre pessoas iguais.

Freire (2019) ainda enfatiza que a forma como deve ocorrer esse diálogo precisa ser observada. A escola precisa falar 'com' os sujeitos e escutá-los se, de fato, deseja buscar uma verdadeira experiência democrática. Neste sentido, precisamos desconstruir a forma autoritária de falar em uma perspectiva hierarquizada. Falar 'com' implica na construção de uma relação horizontal e dialógica, que provoca o desprendimento, para fazer uma escuta mais atenta às vozes vibrantes dos sujeitos que compõem a EJA, onde não haja superiores ou inferiores, mas pessoas iguais. O que deve existir é o colóquio respeitoso onde os sujeitos podem, por meio da efetiva participação, ser desafiados a compreender os processos histórico sociais e as próprias experiências.

$\mathrm{Na}$ experiência de falar 'com' os sujeitos, a escola da EJA potencializa a condição de seus estudantes serem partícipes do poder no contexto da gestão democrática. Freire (2011) acredita que a democracia não é apenas uma forma política, mas, também, uma forma de vida caracterizada pela possibilidade de os sujeitos superarem a sua consciência. O diálogo é a condição essencial para a efetivação da democracia e, por conseguinte, à efetivação de mudança, sendo este elemento essencial na democracia.

Por isso, defendemos que a gestão escolar democrática, numa perspectiva freireana envolve a efetivação da participação e da consolidação do diálogo gestor democrático, que seja experienciada pela efetiva participação dos diversos sujeitos que compõem a escola da EJA. De acordo com Freire (2011), não é possível ter democracia sem a participação popular no poder. A escola precisa compreender que a participação popular na condução da gestão é essencial à potencialização e à consolidação das rupturas que se espera, com a educação desenvolvida com sujeitos populares.

Para efetivar participação, a mudança e a efetiva transformação da realidade, com base em Freire (2018, p. 172), é necessário

[...] inaugurar o diálogo corajoso com as massas. Sua legitimidade está no diálogo com elas, não no engodo, na mentira. Não pode temer as massas, a 
sua expressividade, a sua participação efetiva no poder. Não pode negá-las.

Por meio desta efetiva participação é possível à escola da EJA, além de ouvir e dar conta aos sujeitos dos processos, êxitos e equívocos, compartilhar o espaço de poder envolvendo o exercício coletivo de avaliação dos processos e da tomada de decisões.

De acordo com essa compreensão e possibilidade vemos que a gestão escolar, numa perspectiva freireana, envolve uma relação intrínseca entre diálogo, participação e democracia. Temos em Freire (2018, p.108) que "A existência, porque humana, não pode ser muda, silenciosa, nem tampouco pode nutrir-se de falsas palavras, mas de palavras verdadeiras, com que os homens transformam o mundo". Assim, o diálogo é a condição de os sujeitos conjuntamente poderem se expressar. São condições para a transformação da escola da EJA na consolidação de um espaço de efetiva participação democrática.

Freire (2018) ainda acredita que, além do diálogo ser uma exigência existencial, os homens são seres que só podem viver dentro de um contexto de comunicação, pois esta é uma condição essencial à sua humanidade. Privar os sujeitos dessa condição essencial é subjuga-los e transformá-los em coisas, ação que o autor afirma ser própria de opressores, pois é destes o objetivo de negar as condições essenciais para que homens e mulheres intervenham no mundo, modificando a sua condição de existência, com a superação de contradições sociais, políticas e econômicas.

A gestão escolar na perspectiva freireana traz em seu bojo aspectos humanizadores e includentes, assim também os anseios, as vozes e as denúncias dos sujeitos oprimidos retratados por Freire (2018), evidenciando uma postura antiautoritária e dialógica. Toda ação educativa é uma ação política e como tal precisa dar conta de atender às necessidades de emancipação dos sujeitos que a compõe, oportunizando o desenvolvimento do pensamento crítico e possibilidades de atuação efetiva, na direção de operacionalizar mudanças em si mesmos e na sociedade na qual se inserem.

Nesse sentido, entendemos que essa gestão deve-se pautar no diálogo, na escuta sensível e apresentar ações democráticas e participativas como práticas cotidianas, para oportunizar a cooperação e a participação dos sujeitos, denunciando e caminhando 
na contramão das situações de desigualdades sociais, de discriminação e de negação de direitos que os menos favorecidos sofrem cotidianamente. É necessário contribuir, incessantemente, para que saiam da condição de oprimidos e se constituam em parte importante na tomada de decisões na sociedade.

Esse modelo de gestão cuida para que as aprendizagens desenvolvidas na escola sejam significativas e façam sentido para os estudantes que dela participam, atentando para as suas realidades, vivências e necessidades, buscando se aproximar desses sujeitos e dar relevância ao trabalho pedagógico, a fim de alcançar melhores resultados na aprendizagem e o pleno desenvolvimento dos estudantes da EJA.

Em um estudo que discute sobre o gestor escolar inovador, Amorim (2017) aponta que o fomento à participação e à construção de relações democráticas são essenciais à efetivação de uma gestão inovadora. A construção de um espaço inovador onde o gestor tenha consciência de que a gestão escolar é uma ação política, que exige um olhar mais amplo a respeito da escola e da sociedade. De acordo com o autor, o gestor comprometido com a gestão nesta perspectiva considera o espaço da escola como sendo o espaço da práxis, um espaço complexo e diversificado e tem consciência de que a atuação por meio da gestão inovadora é uma bandeira de trabalho dentro das escolas.

A gestão da participação social dos sujeitos da EJA é discutida por Felinto, Araújo e Amorim (2016), autores que afirmam sobre a necessidade de fomentar a participação e a mobilização dos sujeitos para uma ação permeada pelo diálogo, pois, entendem que a escola é o espaço privilegiado para o desenvolvimento do intercâmbio de saberes e da sua potencialização. De acordo com os autores, é preciso que o ponto de partida da ação educativa seja a experiência dos sujeitos, estudantes e professores, visando a problematização do ato educativo, a fala, o pensamento crítico e o estabelecimento de uma relação dialógica, transcendendo a transmissão de conhecimentos.

Dessa forma, compreendemos que a mobilização da participação dos sujeitos da EJA deve ser meta de uma gestão escolar, uma vez que o jovem e o adulto precisam se reconhecer enquanto cidadãos de direitos e precisam desenvolver aprendizagens 
significativas por meio do exercício de uma pedagogia do diálogo, e, transcendendo-a, alcançando uma pedagogia dialética que visa garantir a livre expressão dos sujeitos da EJA a partir da problematização de conflitos por eles vivenciados, fomentando a construção de processos de convivência democrática.

A partir de estudo desenvolvido por Kay, Carrara e Kay (2013) vemos que a gestão democrática, numa perspectiva freireana, tem a participação dos sujeitos em sua centralidade. As experiências de gestão democrática pautam-se na "[...] afirmação da participação como experiência construtiva e qualificadora das relações implicadas." (p. 76). Estas experiências, considerando-se a perspectiva freireana, carregam em si a paciência impaciente em busca da mudança.

De acordo com os autores, as circunstâncias em que as experiências se efetivam apresentam limitações. No entanto, isto não deve culminar na imobilização dos sujeitos. Todas as experiências produzem conhecimentos individuais e coletivos e é rica na sua capacidade de inovar e recriar.

A gestão escolar desenvolvida em uma perspectiva freireana não pode prescindir da participação efetiva dos sujeitos da EJA no espaço de poder. Neste sentido, é imprescindível que a escola de EJA ensine a participação propiciando a efetiva participação a todos, bem como ensine a democracia com a efetivação do ambiente de gestão democrática na escola da EJA.

Torres (2013) quando aborda o modelo pedagógico freireano, observa que o amordaçamento das pessoas é o reflexo de ações contrárias ao diálogo, haja vista que favorece o embaçamento das ideias para fins de dominação, levando os indivíduos a não expressarem seus pensamentos e, portanto, não orquestrarem a luta de classes. O exposto é denunciado por Freire (2018) e sua proposta pedagógica perpassa pela desalienação dos indivíduos através do desenvolvimento do pensamento crítico, permeado pelo diálogo, intentando promover a emancipação dos sujeitos.

Ainda segundo Torres (2013), Paulo Freire confere às questões políticas os maiores entraves da educação em detrimento das questões didático-metodológicas. Suas contribuições buscaram fomentar o desejo de mudança na sociedade por meio da renovação 
das mentes, da construção de um pensamento crítico, que assegurasse aos sujeitos empoderamento e tomada de consciência de sua condição e de participação individual e coletiva na sociedade, com o firme propósito de fazer com que haja equidade nas relações entre os indivíduos inseridos no contexto social.

\section{DISCUSSÃO DOS RESULTADOS}

Os achados evidenciam, a partir da análise das informações produzidas nos três casos estudados, que $76 \%$ dos sujeitos participantes consideram que a gestão de suas escolas é democrática e participativa, ou seja, busca envolver os sujeitos na tomada de decisões, considerando suas opiniões e sugestões na condução das ações da escola. Já $24 \%$ deles sinalizaram que a gestão da escola não é democrática, nem tampouco participativa.

A não consolidação de uma gestão democrática enfraquece a participação popular dos sujeitos da EJA, seguindo na contramão do que Freire (2019, p. 33) asseverou:

Mulheres e homens, seres histórico-sociais, nos tornamos capazes de comparar, de valorar, de intervir, de escolher, de decidir, de romper, por tudo isso é que nos fizemos seres éticos. Só somos porque estamos sendo. Estar sendo é a condição, entre nós, para ser.

A ausência de princípios democráticos na gestão da escola de EJA propicia o desperdício da experiência e dos saberes de sujeitos, homens e mulheres, que estão sendo e intervindo no mundo.

Um ponto importante para a concretização da experiência democrática, envolvendo a participação dos estudantes da EJA, é a atuação do Conselho Escolar, dispositivo que propicia a participação dos diversos sujeitos nos processos gestores da escola. Considerando esta forma de experiência democrática no âmbito das escolas investigadas, $71 \%$ dos sujeitos participantes afirmaram existir o Conselho Escolar, enquanto $29 \%$ sinalizaram não existir o referido dispositivo na escola propiciando práticas democráticas.

A participação factual dos sujeitos estudantes da EJA no Conselho Escolar, em que questões pedagógicas, administrativas e 
financeiras são tratadas e discutidas por todos os membros é apontada por $71 \%$ dos sujeitos participantes. Entretanto, 29\% informaram que essa participação não existe. Segundo a pesquisa, o composto de gestores, coordenadores e de professores é o maior incentivador da participação dos estudantes no Conselho Escolar, sendo apontado por $47 \%$ dos participantes. Em relação às demais categorias, os incentivos são feitos pelos grupos de professores, conforme apontado por 19\%, gestores e professores, também apontado por $19 \%$. Os demais grupos, conforme apresentado no quadro 1 , perfazem $15 \%$.

No tocante à participação dos sujeitos da EJA na gestão escolar, os participantes puderam avaliar a relevância da participação em uma escala variando de zero, equivalente a não importante, a cinco, equivalente a muito importante. As respostas apresentadas pelos participantes revelam a grande significância deste item, onde $87 \%$ avaliaram tanto a participação do professor quanto a do coordenador pedagógico na gestão da escola da EJA como muito importante, ao passo que $13 \%$ afirmam que a participação desses profissionais é importante. Quando a avaliação é referente à participação do estudante da EJA na gestão escolar, $76 \%$ dos participantes afirmaram que é muito importante, enquanto $24 \%$ entendem que é importante.

Quadro 1 - Gestão democrática e participação dos sujeitos da EJA na gestão escolar

\begin{tabular}{|c|l|}
\hline Questões & \multicolumn{1}{|c|}{ Respostas apresentadas pelos sujeitos } \\
\hline $\begin{array}{c}\text { Gestão } \\
\text { Democrática }\end{array}$ & $\begin{array}{l}76 \% \text { consideram a gestão escolar democrática. } \\
24 \% \text { não consideram a gestão democrática. }\end{array}$ \\
\hline $\begin{array}{c}\text { Conselho } \\
\text { Escolar }\end{array}$ & $\begin{array}{l}71 \% \text { afirmam que escola possui Conselho Escolar. } \\
29 \% \text { informam que não há Conselho Escolar. }\end{array}$ \\
\hline $\begin{array}{c}\text { Representação } \\
\text { estudantil }\end{array}$ & $\begin{array}{l}71 \% \text { afirmam que há representação de estudante da EJA no } \\
\text { Conselho Escolar. } \\
29 \% \text { apontam que não há representação do estudante da } \\
\text { EJA no Conselho Escolar. }\end{array}$ \\
\hline
\end{tabular}




\begin{tabular}{|c|c|}
\hline $\begin{array}{c}\text { Quem } \\
\text { estimula a } \\
\text { participação }\end{array}$ & $\begin{array}{l}47 \% \text { gestor, coordenador e professor. } \\
19 \% \text { gestor e professor. } \\
19 \% \text { professor. } \\
5 \% \text { gestor, coordenador, professor e funcionários. } \\
5 \% \text { professor e coordenador. } \\
5 \% \text { gestor. }\end{array}$ \\
\hline \multirow{3}{*}{$\begin{array}{l}\text { Relevância da } \\
\text { participação } \\
\text { na gestão } \\
\text { escolar }\end{array}$} & $\begin{array}{l}87 \% \text { acreditam que a participação do professor é muito } \\
\text { importante. } \\
13 \% \text { entendem que a participação do professor é } \\
\text { importante. }\end{array}$ \\
\hline & $\begin{array}{l}87 \% \text { apontam a participação do coordenador como muito } \\
\text { importante. } \\
13 \% \text { afirmam que a participação do coordenador é } \\
\text { importante. }\end{array}$ \\
\hline & $\begin{array}{l}76 \% \text { apontam a participação do estudante da EJA como } \\
\text { muito importante. } \\
24 \% \text { afirmam que a participação do estudante da EJA é } \\
\text { importante. }\end{array}$ \\
\hline
\end{tabular}

Fonte: Elaborado pelos pesquisadores (2019).

Quando analisamos os achados da pesquisa e estabelecemos um diálogo com Freire (2011), que declarou ser a democracia palco de discussões que problematizam a vida, haja vista que antes de assumir-se enquanto organização política, revela-se nas atitudes e direcionamentos dos indivíduos pautados em constantes reflexões e discussões, ratificamos a relevância de se protagonizar a cooperação da comunidade escolar no fortalecimento da gestão da escola. Assim, é importante que se busque uma essência que seja popular, participativa e includente, que se escute aos que dela coadjuvam sem preconceitos e acepções de qualquer natureza, valorando as ideias, anseios e decisões tomadas na coletividade.

No tocante à participação dos estudantes da EJA, para que se constituam enquanto atores notáveis na tomada de decisões desse espaço educativo, corroboramos com o pensamento freireano, quando afirma que:

[...] nos tornamos capazes de intervir na realidade, tarefa incomparavelmente mais complexa e geradora de novos saberes do que simplesmente a de nos adaptar a ela. É por isso também que não me 
parece possível nem aceitável a posição ingênua ou, pior, astutamente neutra de quem estuda, seja o físico, o biólogo, o sociólogo, o matemático, ou o pensador da educação. Ninguém pode estar no mundo, com o mundo e com os outros de forma neutra. (FREIRE, 2019, p. 77)

Destacamos que essa participação, tão asseverada pelos teóricos que dialogam juntamente conosco neste artigo, sobretudo quanto aos ideários freireanos de participação popular de forma autônoma e lúcida, é condição sine qua non para que se efetive uma gestão realmente democrática que permita a participação popular de forma crítica e produtiva.

A análise das informações produzidas revela ainda que nos três casos estudados há uma diversidade de dispositivos por meio dos quais os sujeitos efetivam a participação. A sugestão de ações e / ou atividades e a avaliação das ações e projetos da escola foram os elementos mais apontados pelos sujeitos, dezenove e treze sujeitos respectivamente. $E$, conforme as observações e informações apresentadas pelos participantes, se efetivam por meio da escuta dos estudantes pelos gestores.

Definição de projetos educativos, decisões financeiras, cada um apontado por onze sujeitos, e a avaliação do resultado da aprendizagem, apontada por nove sujeitos, assumem o segundo lugar entre os elementos mais evidenciados. A definição dos projetos ocorre tanto a partir da escuta dos sujeitos fora do Conselho Escolar quanto nas reuniões do grupo colegiado. Já as decisões financeiras e a avaliação do resultado da aprendizagem envolvem a participação dos sujeitos através do Conselho Escolar.

As decisões administrativas, a avaliação do desempenho da gestão, apontadas por oito sujeitos cada, e a avaliação do desempenho de professores e dos coordenadores, apontada por sete sujeitos, também são efetivados com a participação nas reuniões do grupo colegiado. A elaboração do Projeto Político Pedagógico (PPP) é apontada, mas é notório que não há uma expressiva participação dos sujeitos, considerando-se que apenas seis participantes sinalizaram o dispositivo enquanto espaço de participação do estudante da EJA. 
O projeto político pedagógico, ao se constituir em processo democrático de decisões, preocupa-se em instaurar uma forma de organização do trabalho pedagógico que supere os conflitos, buscando eliminar as relações competitivas, corporativas e autoritárias, rompendo com a rotina do mando impessoal e racionalizado da burocracia que permeia as relações no interior da escola, diminuindo os efeitos fragmentários da divisão do trabalho que reforça as diferenças e hierarquiza os poderes de decisão

O projeto político pedagógico, ao se constituir em processo democrático de decisões, preocupa-se em instaurar uma forma de organização do trabalho pedagógico que supere os conflitos, buscando eliminar as relações competitivas, corporativas e autoritárias, rompendo com a rotina do mando impessoal e racionalizado da burocracia que permeia as relações no interior da escola, diminuindo os efeitos fragmentários da divisão do trabalho que reforça as diferenças e hierarquiza os poderes de decisão.

Gráfico 1 - Dispositivos de participação na percepção dos sujeitos da investigação

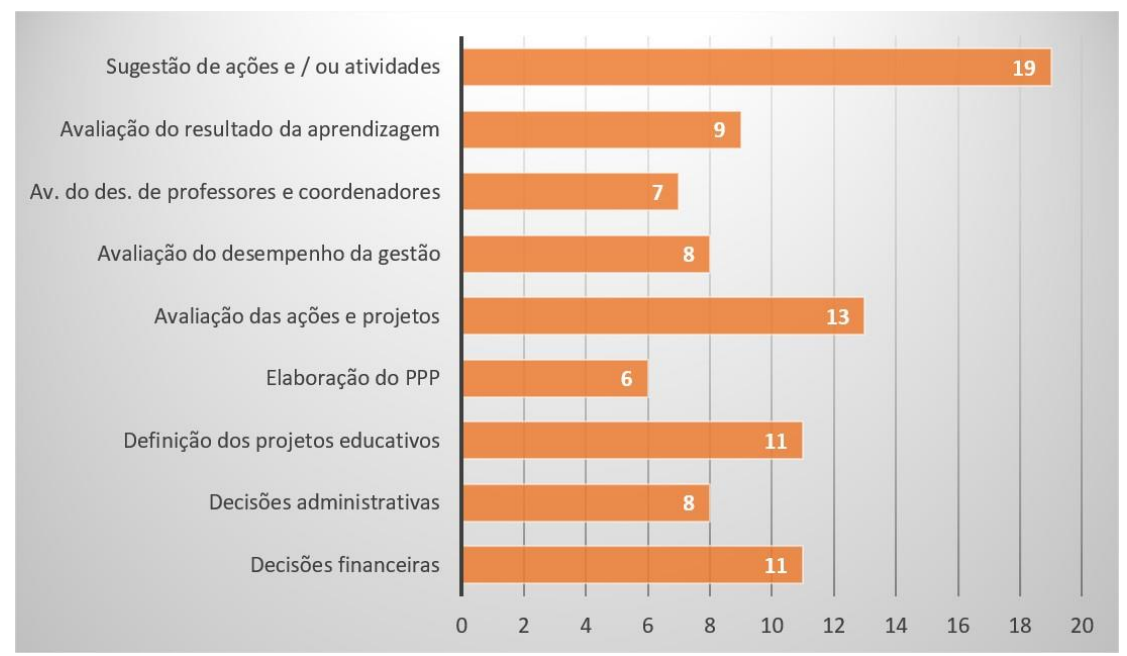

Fonte: Elaborado pelos pesquisadores (2019). 
Os achados da pesquisa sedimentaram algumas ideias e aclararam outras quanto aos resultados advindos de uma prática gestora democrática e de participação popular. Desta forma, fica evidente que:

- Os sujeitos compreendem a relação entre gestão democrática e efetivação da participação;

- As escolas propiciam diferentes mecanismos de participação para os sujeitos da EJA;

- O conselho escolar é um dispositivo fundamental para consolidar a participação interventiva nos processos da gestão;

- O Projeto Político Pedagógico ainda carece de uma participação mais efetiva do sujeito da EJA em sua elaboração / revisão;

- Há contrastes em relação as três escolas envolvendo a efetivação da gestão democrática, os dispositivos para consolidar a participação dos sujeitos da EJA e a dinâmica do cotidiano escolar refletindo a concepção dos sujeitos.

Assim, podemos afirmar que a concepção freireana de diálogo, participação e de relações democráticas, que são utilizadas para a efetivação de mudanças, estão permeadas, de alguma maneira, nas concepções apresentadas pelos sujeitos da investigação.

Nesse sentido, fica evidente junto aos sujeitos investigados, a importância da concepção freireana para o aprimoramento democrático da gestão escolar, valorizando-se a participação, o diálogo e a democracia no âmbito das decisões institucionais de cada escola.

\section{CONSIDERAÇÕES FINAIS}

Na finalização desta pesquisa podemos afirmar que a gestão escolar municipal em Salvador/Ba tem se efetivado, em parte, pelos caminhos da gestão democrática considerando a perspectiva freireana de participação popular. Isso foi evidenciado nos achados 
da pesquisa, ao ouvir as vozes dos sujeitos e compreender a maneira como participam ou não da gestão de suas escolas. Compreendemos que há muito o que labutar para que essa perspectiva de gestão seja colocada em prática na escola da EJA. Muitos dos sujeitos partícipes desta modalidade de ensino ainda permanecem sem poder fazer ecoar o que acreditam ser relevante para a sua própria formação, o que viabilizaria o exercício pleno de cidadania, além da formação de uma postura contra hegemônica na sociedade.

Ficou constatado no andamento do trabalho que a gestão da escola pública, numa perspectiva freireana ocorre em diferentes níveis nas três escolas estudadas, revelando que a participação dos sujeitos da Educação de Jovens e Adultos nos processos de gestão da escola precisa ser fortalecida para que a escola da EJA possa ser construída com os sujeitos, dialogando com as suas necessidades e da sua comunidade, colaborando com rupturas radicais necessárias, caminhando na direção de uma educação libertária idealizada por Paulo Freire, com alcance para além das paredes da escola, envolvendo e influenciando não somente a comunidade escolar, mas a sociedade na qual os sujeitos se inserem compondo parte fundante dela.

Da mesma forma, ficou evidenciado que a gestão escolar numa perspectiva freireana implica na efetivação da gestão democrática, onde a democracia precisa ser vivida, experienciada com a participação dos sujeitos da EJA. É necessário firmar a condução dos processos de gestão da escola, modificando alicerces e rompendo com as barreiras antigas, firmadas num processo antidemocrático que não legitimava esses sujeitos como indivíduos pensantes e de vozes vibrantes que ecoam suas lutas. Haja vista que, historicamente, sempre sofreram com a negação de direitos e ainda sofrem, mas que, com tudo isso, não desistem e tentam, ainda que a passos não muito largos e de maneira resiliente, avançar.

Finalmente, devemos considerar que a gestão da escola de EJA, onde se busca efetivar a gestão numa perspectiva freireana envolve a participação popular, exige a construção do diálogo permanente entre os diversos sujeitos do ambiente da escola: alunos, professores, gestores e servidores técnico-administrativos. Só assim será possível compreender o que pensam, sentem e desejam os 
estudantes, ampliando, dessa forma, a capacidade de inovar os processos de participação na gestão escolar e a qualidade da educação desenvolvida com os sujeitos populares.

\section{REFERÊNCIAS}

AMORIM, Antonio. Gestor escolar inovador: educação da contemporaneidade. Revista lusófona de Educação, n. 35, p. 67-82. 2017

ANDRÉ, Marli. O que é um estudo de caso? Revista da FAEEBA Educação e Contemporaneidade, Salvador, v. 22, n. 40, p. 95-103, jul./dez. 2013.

CHIZZOTTI, Antonio. Pesquisa em ciências humanas e sociais [livro eletrônico]. São Paulo: Cortez, 2018.

FELINTO, M. A. S.; ARAÚJO, A. R. de; AMORIM, A. A gestão da participação social e dos processos pedagógicos para integrar os educandos da EJA no âmbito da escola pública. In: Encontro Internacional de Formação de Professores e Fórum Permanente de Inovação Educacional, Aracaju. v. 9. p. 1-14, 2016.

FREIRE, Paulo. Educação como prática da liberdade. 34. ed. Rio de Janeiro: Paz e Terra, 2011.

FREIRE, Paulo. Pedagogia da autonomia: saberes necessários à prática educativa. Rio de Janeiro: Paz e Terra, 2019.

FREIRE, Paulo. Pedagogia do oprimido. Rio de Janeiro: Paz e Terra, 2018.

GIL, Antonio Carlos. Métodos e técnicas de pesquisa social. 7. ed. São Paulo: Atlas, 2019.

HAGUETTE, Teresa Maria Frota. Metodologias qualitativas na sociologia. Petrópolis: Vozes, 2013.

KAY, Márcia; CARRARA, Maurício; KAY, Patrícia. Paulo Freire e a gestão democrática: uma leitura da experiência da participação na secretaria de educação do município de Santo André/SP. R. Adm. Educacional, Recife, v. 3, n. 9, p. 53-81, jan./jun., 2013. 
MINAYO, Maria Cecília de Souza. (org.) Pesquisa social: teoria, método e criatividade. Petrópolis, RJ: Vozes, 2016.

RICHARDSON, Roberto Jarry. Pesquisa social: métodos e técnicas. 3. ed. São Paulo: Atlas, 2015.

TORRES, Carlos Alberto. Fifty Years After Angicos Paulo Freire, Popular Education and the Struggle for a Better World that is Possible. Rev. Lusófona de Educação, Lisboa, n. 24, p. 15-32, 2013. VEIGA, Ilma Passos Alencastro. Projeto político-pedagógico da escola uma construção possível. Campinas-SP: Papirus Editora, 2013.

YIN, Robert K. Estudo de caso: planejamento e métodos. Trad. Daniel Grassi. 5 ed. Porto Alegre: Bookman, 2014.

Submetido em: Abril/ 2020.

Aceito em: Dezembro/ 2020. 
